Industrial Health, 1984, 22, 305-318

\title{
Cytogenetic Analysis of Peripheral Blood Lymphocytes from Stainless Steel Welders
}

\author{
Kimiko KOSHI, Takashi YAGAMI* and Yoshifumi NAKANISHI
}

\author{
National Institute of Industrial Health, \\ 21-1, Nagao-6-chome, Tama-ku, Kawasaki-shi, Kanagawa 214, Japan \\ * Second Department of Internal Medicine, Showa University, School of Medicine, \\ 1-5-8, Hatanodai, Shinagawa-ku, Tokyo 142, Japan
}

(Received September 5, 1984)

\begin{abstract}
The frequency of sister chromatid exchanges (SCE), structural chromosomal aberrations and the number of chromosomes in the peripheral blood lymphocytes from stainless steel welders were studied. The surveys were carried out three times during a period of three years. There were no significant differences in the mean value and variance of SCE frequency among these three surveys both in the welders and in the controls. In the results from these three surveys, there were statistical differences in the variance of SCE frequency between the welder and control groups. Futhermore, there was significant difference in the mean values of SCE frequency between smokers and non-smokers among the welders. The incidences of structural chromosomal aberrations in the welders were slightly but sinificantly higher than those in the controls with respect to aberrant metaphases, chromatid and chromosome gaps, chromatid breaks, dicentric chromosomes and chromatid exchanges. As for the number of chromosomes, two welders with 47 chromosomes in about $70 \%$ of total metaphases were found, and their chromosome findings were confirmed to be $46, X Y / 47, X X Y$.

Key words : SCE-Chromosomal aberration-Chromosome number-Stainless steel -Welder-Lymphocyte-Smoker
\end{abstract}

\section{INTRODUCTION}

Stainless steel welding produces a fume containing various gases and small particles mainly consisting of complexes of metallic oxide such as chromium, nickel, manganese and iron. Furthermore, ultraviolet rays and ozone are also generated during the arc-welding process.

In a previous paper, ${ }^{1}$ the fume particles from stainless steel welding have been shown to produce an increase of sister chromatid exchange (SCE) frequency and chromosomal aberrations in cultured Chinese hamster cells. Furthermore, ozone ${ }^{2-5}$ ) and ultraviolet rays $^{6-8)}$ have also been reported to cause chromosomal changes in cultured cells. A report ${ }^{9)}$ has been made on the fact that the incidence of 
pulmonary tumor is approximately four times the expected value among stainless steel welders and another ${ }^{00}$ indicated an increase in the incidence of throat cancer among these welders. An increase of SCE frequency and chromosomal aberration in the peripheral lymphocytes has been found among workers exposed to mutagenic or carcinogenic chemical substances such as benzene, ${ }^{11)}$ vinyl chloride monomer ${ }^{12)}$ and styrene. ${ }^{13)}$

The purpose of the present study was to investigate possible chromosomal changes in stainless steel welders exposed to various mutagenic factors in stainless steel welding.

\section{SubJects AND Methods}

\section{Subjects:}

Our study group was composed of 17 male workers in the first survey and 44 male workers in the second and the third surveys. They had been constantly engaged in stainless steel welding using manual metal arc (MMA) welding and metal inert gas arc (MIG) welding for periods ranging from 5 to 20 years (mean value, 12.1 years) at the time of these surveys. They were aged 25-47 years (mean age, 33.5 years). The relative proportion of work time on MMA welding and MIG welding was about half and half during their careers. Occasionally, they had participated in aluminium welding.

The control group was composed of 6 males in the first survey and 7 males in the second survey. They were office workers in the same factory aged 30-40 years (mean age, 35.1 years). In the third survey we selcted 20 workers in the research section (non-chemical) in the same factory aged 18-49 years (mean age, 28.9 years).

The subjects were questioned about medical X-ray exposure and drug intake to exclude those subjects who might have been exposed to other known chromosome-damaging agents. Furthermore, a questionaire was distributed to quantitate the intake of cigarettes, alcohol and coffee.

\section{Working environment and exposure:}

Because of improvements made in the working environment of the welding place in 1974, sufficient ventilation could be obtained by local exhaust and a fan in the ceiling. The general air concentrations of air and gases in the work place were surveyed in 1978 ${ }^{14}$ ) and the results are shown in Tables 1 and 2.

The personal exposure of stainless steel welders measured using personal dust samplers varied from 3.95 to $174.02 \mathrm{mg} / \mathrm{m}^{3}$, showing large individual differences. ${ }^{14,15)}$ The exposure volume according to the manner of work also showed great differnces, making it difficult to obtain an exposure concentration. Since a dust respirator with fibrous active carbon filter against ozone was worn by all our welders, they seemed to inhale only small volumes of fumes and ozone. However, 
Table 1. General air concentrations of fumes and gases in the welding place

\begin{tabular}{lllc}
\hline & & \multicolumn{2}{c}{ Ventilation } \\
\cline { 3 - 4 } & & \multicolumn{1}{c}{ Operation } & Non-operation \\
\hline Fume & $\mathrm{mg} / \mathrm{m}^{3}$ & $0.330-0.868$ & $2.268-3.865$ \\
$\mathrm{NO}_{2}$ & $\mathrm{ppm}$ & $0.192-0.324$ & $0.293-0.449$ \\
$\mathrm{CO}$ & $\mathrm{ppm}$ & $0.49-2.40$ & $0.61-4.25$ \\
$\mathrm{O}_{3}$ & $\mathrm{ppm}$ & $0.008-0.01$ & $0.002-0.12$ \\
\hline
\end{tabular}

Table 2. General air concentrations of fumes and gases in semi-closed vessel type structure

\begin{tabular}{llcc}
\hline & & \multicolumn{2}{c}{ Ventilation } \\
\cline { 3 - 4 } & & Operation & Non-operation \\
\hline $\mathrm{O}_{3}$ & $\mathrm{ppm}$ & $0.01-0.06$ & $0.028-0.088$ \\
Fume & $\mathrm{mg} / \mathrm{m}^{3}$ & 2.55 & 11.37 \\
$\mathrm{NO}_{2}$ & $\mathrm{ppm}$ & 0.530 & 1.150 \\
$\mathrm{CO}$ & $\mathrm{ppm}$ & $30-45$ & 100 \\
\hline
\end{tabular}

the large differences in personal exposure concentration suggest inhalation of fumes and ozone due to leakage of respirators and other reasons. Furthermore, the welders wore the cloth hoods for protection against intensive ultraviolet rays.

\section{Chromosome analysis:}

Investigations of chromosome analysis were carried out three times during the three years.

Whole blood sampled from the cubital vein of each subject was cultured in minimal essential medium (MEM) supplemented with $10 \%$ fetal calf serum, penicillin, streptomycin and phytohemaglutinin for 48 hours and 72 hours at $37^{\circ} \mathrm{C}$ in a $5 \% \mathrm{CO}_{2}$ atmosphere. Four hours prior to harvest, colcemid was added to arrest mitotic cells in metaphase. Chromosomal preparations were made by the conventional air drying method and staining was carried out with Giemsa solution for study of structural chromosomal aberrations. The structural chromosomal aberrations were examined in more than 50 metaphases per subject in each survey and the specimens showing findings of aberration were photographed. At least eight microphotographs per subject in each survey were taken even in the absence of any abnormal findings. When the types of chromosomal aberrations could not be decided on the basis of the microphotographs, karyotype analysis was done. The number of chromosomes was scored on the microphotographs. For the observation of SCE, the peripheral blood lymphocytes were cultured in the above-mentioned culture solution with the addition of $20 \mu \mathrm{g} / \mathrm{ml}$ of 5-bromodeoxyuridine (BrdU) for 70 hours. The addition of colcemid and chromosome preparation was the same as above. The differential staining of SCE was carried out according to 
Goto et al. ${ }^{16)}$ In order to determine the number of SCE per cell, 25 cells were scored on the microphotograph. For the chromosome analysis, the all subjects were randomly coded and the blood culture, chromosome preparation and observation of chromosomes were carried out blindly. In the first and second surveys the whole blood samples from welders and controls were cultured at the same time. In the third survey, however, they were carried out on the different occasions.

\section{Chromium in the urine:}

Spot urine samples were collected during the workday, and analysis of chromium in the urine was made with a direct flameless atomic absorption spectrometric method.

\section{Clinical laboratory tests:}

Red blood cell counts ( $R B C)$, white blood cell counts (WBC), hemoglobin concentration $(\mathrm{Hb})$, hematocrit value $(\mathrm{Ht})$ and hemograms were determined by conventional methods. Assays for four serum enzymes, glutamic oxalactic transaminase (GOT), glutamic pyruvic transaminase (GPT), r-glutamic transpeptidase (r-GTP) and lactic dehydrogenase (LDH) were performed according to the routine method.

\section{RESUlts}

1. The frequency of sister chromatid exchanges:

Figure 1 shows the results of SCE frequency of cultured lymphocytes from stainless steel welders together with controls in the three surveys. There were no significant differences in the mean value $(p>0.05)$ and variance $(p>0.05)$ of SCE frequency among the three surveys both in the welders and in the controls. In the results from three surveys there were statistical differnces (the $1 \mathrm{st}, \mathrm{p}<0.05$, the 2nd $\mathrm{p}<0.05$, the 3rd, $\mathrm{p}<0.01$ ) in the variance of SCE frequency between the exposed and control groups. In the results from the total of the three surveys, there were statistical differences $(p<0.01)$ in the variance of SCE frequency between the exposed and control groups. These mean values and standard

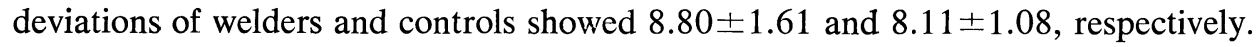

When comparing SCE frequency in smokers with that of non-smokers, there was a significant difference $(p<0.01)$ among the welders. These results are shown in Figure 2. In the control groups, SCE frequency in smokers was higher than that in non-smokers, but this difference was not significant $(p>0.05)$. The reason for this might be the small number of data in the controls. The relationship between the number of cigarettes smoked per day and the SCE frequency in the welder group is shown in Table 3. As shown in the table, a clear correlation was not observed. There was no significant difference $(p>0.05)$ in the SCE frequency 


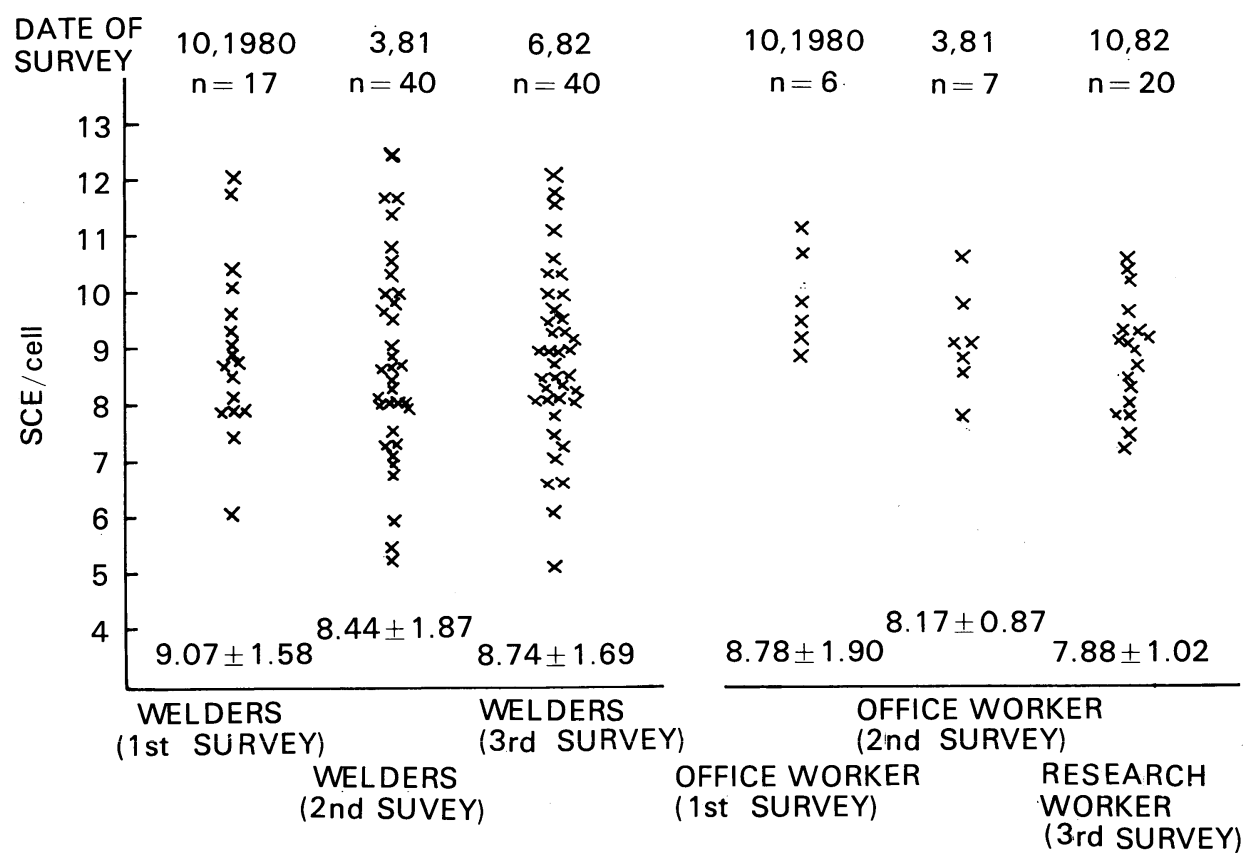

Fig. 1. SCE frequencies in the lymphocytes from stainless steel welders and controls.

* In the 2 nd and the 3rd survey 4 welders were not determined for SCE analysis.

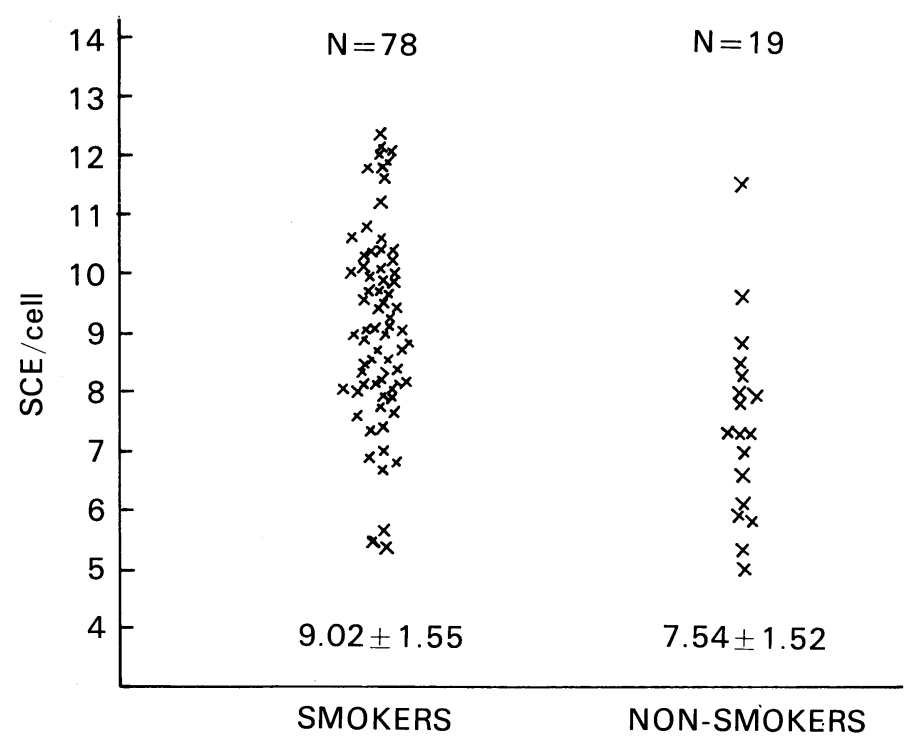

Fig. 2. SCE frequencies in the lymphocytes from smokers and non-smokers in the welder group. 
Table 3. Relationship between SCE frequency and number of cigarettes smoked per day

\begin{tabular}{|c|c|c|c|c|c|}
\hline $\begin{array}{l}\text { Number of } \\
\text { cigarettes/day }\end{array}$ & 0 & $1-9$ & $10-19$ & $20-29$ & $>30$ \\
\hline $\mathrm{n}$ & 18 & 7 & 21 & 26 & 7 \\
\hline $\begin{array}{l}\text { SCE frequency } \\
(\text { mean } \pm \text { S.D. }\end{array}$ & $7.20 \pm 1.27^{*}$ & $9.36 \pm 1.13$ & $9.26 \pm 1.36$ & $9.05 \pm 1.78$ & $9.38 \pm 1.95$ \\
\hline
\end{tabular}

Table 4. Relationship between duration of employment and SCE frequency

\begin{tabular}{cccc}
\hline Duration (years) & $\mathrm{n}$ & Mean value & $\overline{\mathrm{u}}$ \\
\hline$<11$ & 18 & 8.81 & 1.13 \\
$\geqq 11$ & 22 & 8.75 & 1.64 \\
\hline
\end{tabular}

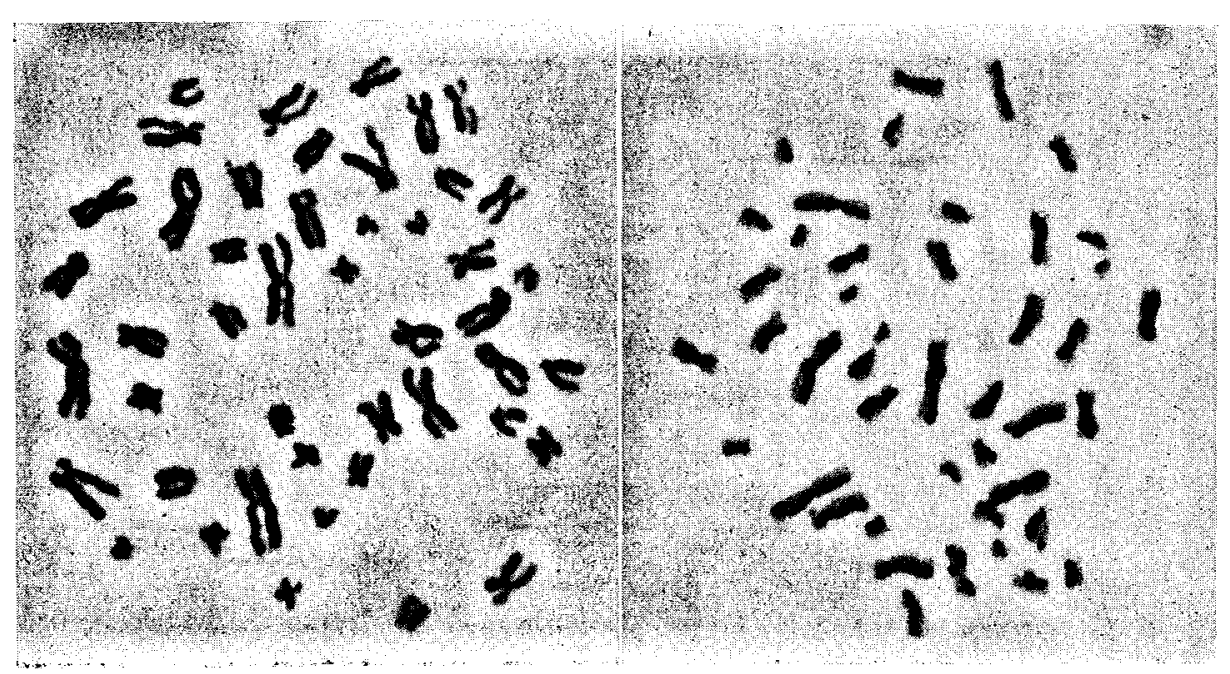

Fig. 3. Findings of SCE frequency in the lymphocytes.

between welders employed more than 11 years and less than 11 years as shown in Table 4. The microphotographs of SCE frequency in the lymphocytes are shown in Figure 3.

2. The frequency of structural chromosomal aberrations:

In the results from the total of the three surveys, the incidences of structural chromosomal aberrations of cultured lymphocytes from stainless steel welders were compared with those of the controls. The findings are shown in Table 5. As shown in the table, the incidence of structural chromosomal aberrations in the welder groups was higher than that in the controls with respect to aberrant metaphases, chromatid and chromosome gaps, chromatid breaks, dicentric 

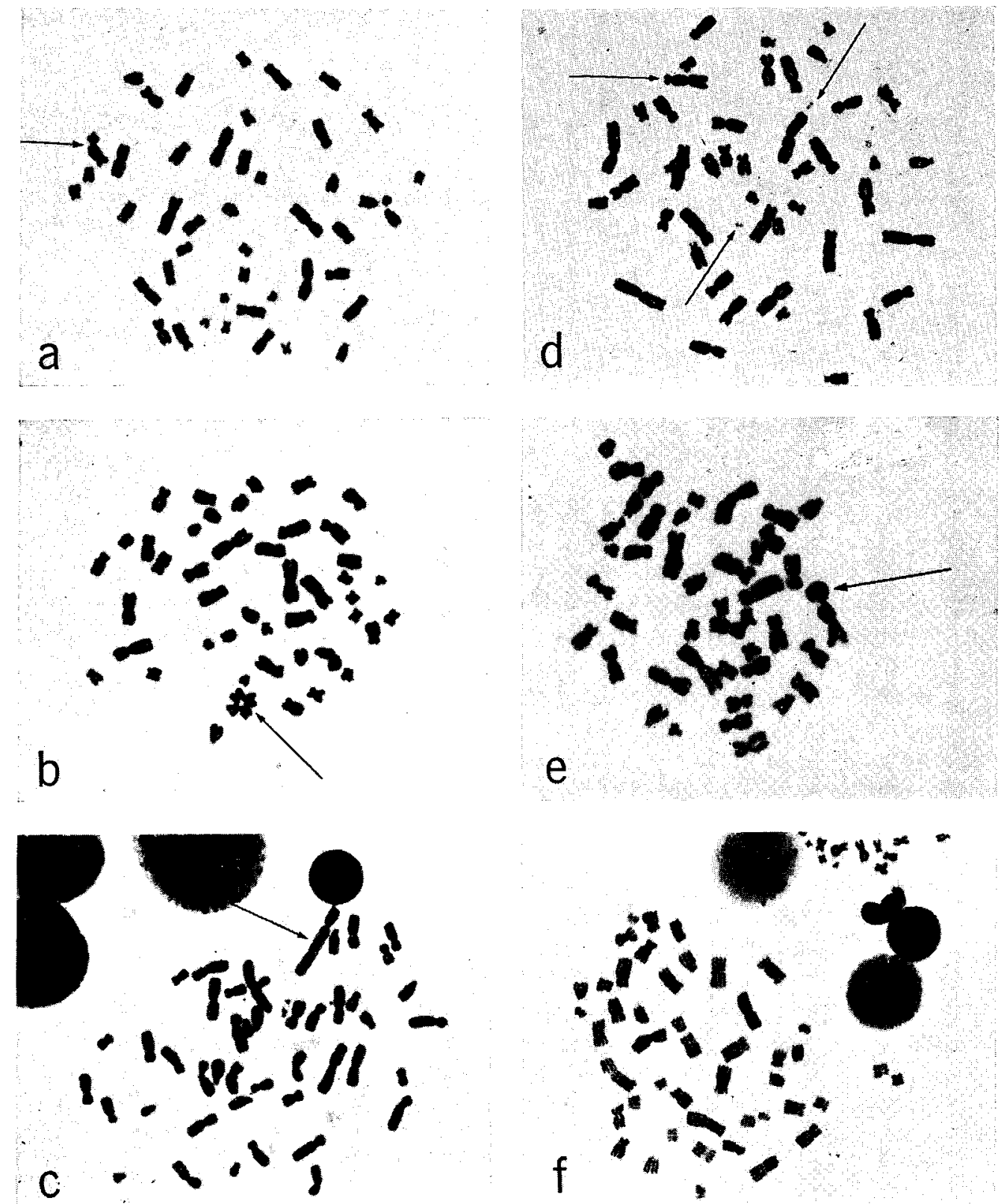

Fig. 4. Aberrant findings of chromosomes in the welder group.
a) Chromatid break
b) Chromatid exchange
c) Translocation
d) Dicentric chromosome and two minutes
e) Ring chromosome
f) Endoreplication 
Table 5. The incidences of chromosomal aberrations

\begin{tabular}{lcccc}
\hline & \multicolumn{2}{c}{ Welder group } & \multicolumn{2}{c}{ Control group } \\
\cline { 2 - 5 } & Number & $\%$ & Number & $\%$ \\
\hline Total cells scored & 8340 & & 3554 & \\
Aberrant metaphase & 392 & $4.7^{* *}$ & 117 & 3.2 \\
Chromatid gap & 294 & $3.5^{* *}$ & 74 & 2.1 \\
Chromosome gap & 27 & $0.3^{*}$ & 8 & 0.23 \\
Chromatid break & 28 & $0.3^{*}$ & 7 & 0.2 \\
Chromosome break & 1 & 0.01 & 0 & 0 \\
Isochromatid fragment & 48 & 0.57 & 16 & 0.45 \\
Decentric chromosome & 8 & $0.1^{*}$ & 1 & 0.03 \\
Ring chromosome & 2 & 0.02 & 0 & 0 \\
Chromatid exchange & 8 & $0.1^{*}$ & 1 & 0.03 \\
Translocation & 1 & 0.01 & 0 & 0 \\
Endoreduplication & 3 & 0.04 & 0 & \\
\hline$* * \mathrm{p}<0.01$ * $<0.05$ & & & &
\end{tabular}

chromosomes and chromatid exchanges. Some samples of microphotographs showing aberrant findings in the welder groups are shown in Figure 4. Figure 5 shows the incidence of aberrant metaphases in individual welders and controls in the third survey. As shown in the figure, in both 48-hour and 72-hour cultures in the control group, the subjects who had aberrant metaphase in $4 \%$ were the most numbers and almost subjects had less than $6 \%$ aberrant metaphases. In the welder group, on the other hand, the subjects who had more than $10 \%$ aberrant

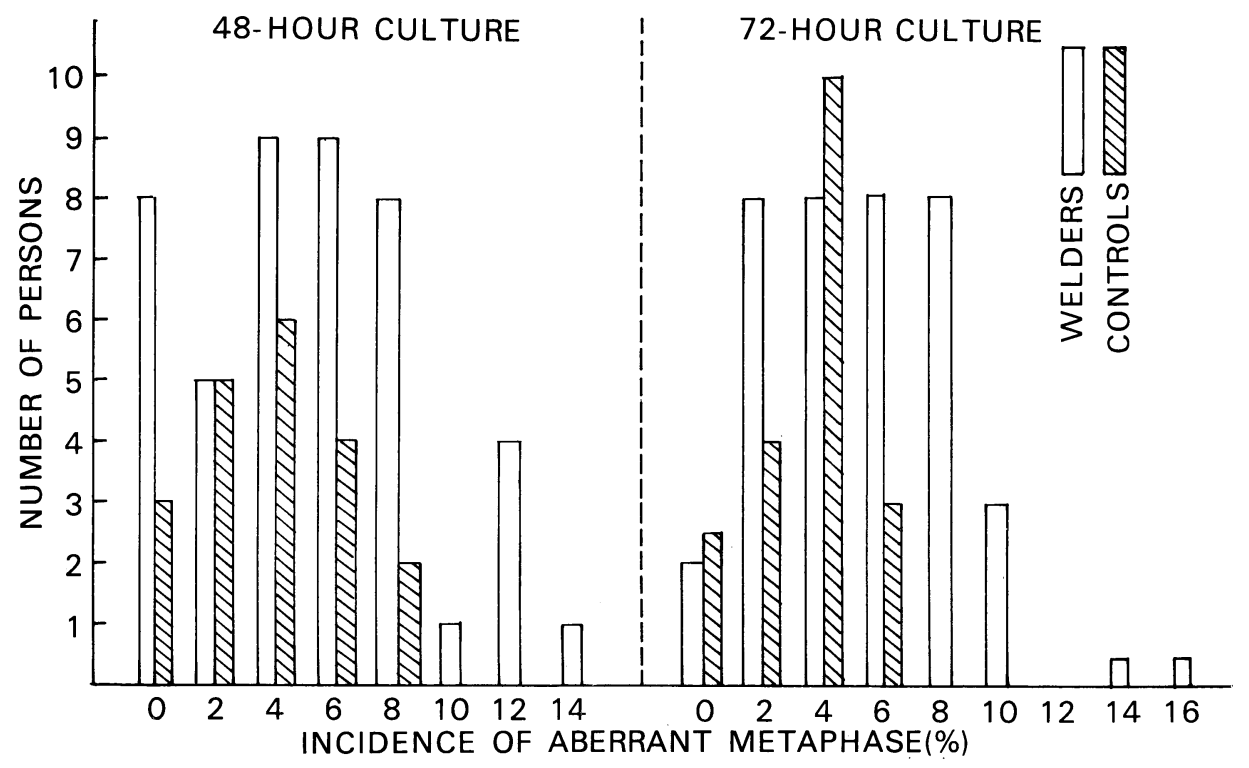

Fig. 5. The incidence of aberrant metaphases in individuals. 
metaphases were found.

\section{Chromosome number:}

The worker group included two subjects in whom metaphases with 47 chromosomes represented approximately 70\%. Table 6 shows the distribution of the numbers of chromosomes of these welders. Figure 6 discloses the karyotype of 47 chromosomes. As shown in the figure, the extra chromosome seems to be an extra $X$ chromosome. In the two welders with 47 chromosomes, an $\mathrm{X}$ chromatin was observed in approximately $10 \%$ of the cells in the oral mucosa of the cheeks. These photographs are shown in Figure 7. Thus it was considered that

Table 6. The distribution of the aberrant number of chromosomes in two welders

\begin{tabular}{crrrrr}
\hline Welder & & No. 1 & \multicolumn{3}{c}{ No. 2} \\
\cline { 4 - 6 } $\begin{array}{c}\text { Chromosome number } \\
\text { Time of survery }\end{array}$ & I & II & III & I & II \\
\hline$<46$ & $1 / 50$ & $2 / 50$ & $3 / 50$ & $4 / 50$ & $4 / 50$ \\
46 & $3 / 50$ & $8 / 50$ & $4 / 50$ & $6 / 50$ & $10 / 50$ \\
47 & $46 / 50$ & $40 / 50$ & $43 / 50$ & $36 / 50$ & $33 / 50$ \\
$>47$ & $0 / 50$ & $0 / 50$ & $0 / 50$ & $4 / 50$ & $3 / 50$ \\
\hline
\end{tabular}

\section{II II}

\section{8}
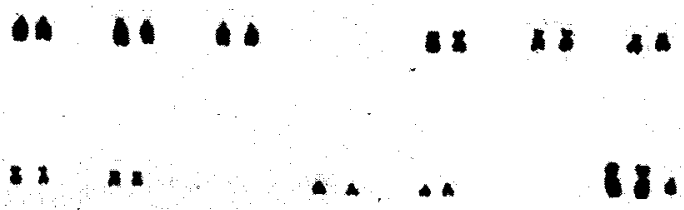

Fig. 6. The Karyotype of 47 chromosomes.

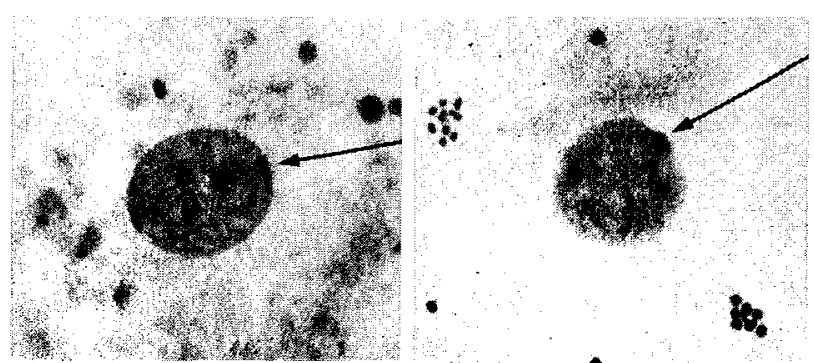

Fig. 7. A X-chromatin of the cell in the oral mucosa of the cheeks. 


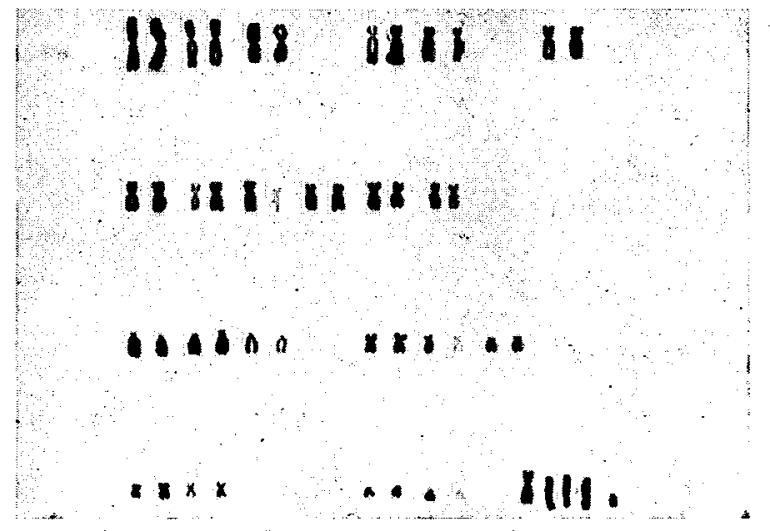

Fig. 8. The karyotype of 49 chromosomes.

the chromosomes of these welders were $46, \mathrm{XY} / 47, \mathrm{XXY}$. As shown in Table 6, one of the two subjects had a few metaphases with more than 47 chromosomes, and the extra chromosomes were attributed to $\mathrm{X}$ on the basis of his karyotype as shown in Figure 8.

\section{Chromium concentration in the urine:}

Figure 9 shows the results of chromium concentration in the urine from welders together with controls. As shown in the figure, the chromium concentraiton in the urine from welders ranged from 3.0 to $59.0 \mu \mathrm{g} / \mathrm{l}$, mean value $9.8 \pm 9.2 \mu \mathrm{g} / \mathrm{l}$, while that from controls was between 3.0 and $6.0 \mu \mathrm{g} / l$, mean value $4.1 \pm 1.2 \mu \mathrm{g} / l$.

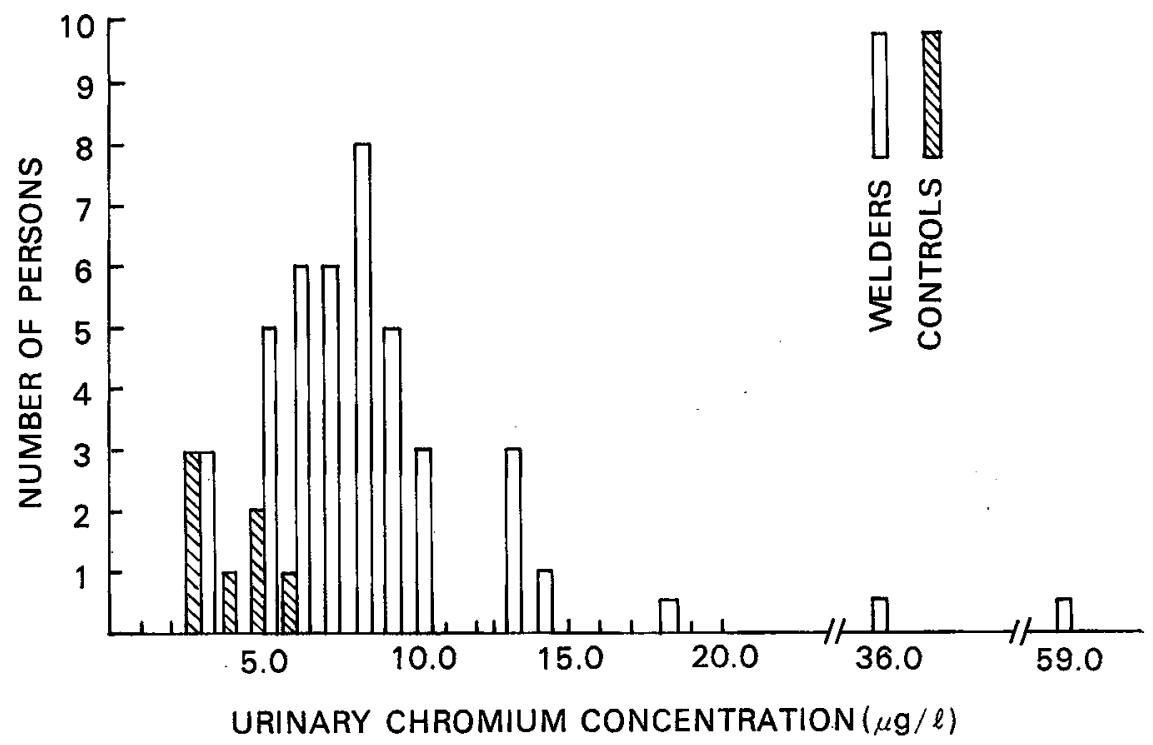

Fig. 9. Urinary chromium concentrations in stainless steel welders and controls. 


\section{Clinical blood examination:}

Neither the welder nor the control group exhibited any abnormal finding of RBC, WBC, Hb, Ht, hemogram, GOT, GPT, LDH or $\gamma$-GTP.

\section{Discussion}

The present results suggested that the chromosomes of the peripheral lymphocytes in stainless steel welders showed slight but significant differences from the control group.

Since the working environment was improved in 1974, and since the workers wore personal respirators, the current exposure volume of fumes as a group seems small. However, some of the subjects had been working before the improvement, and the effects of a personal respirator differ remarkably in some cases depending on the manner of use; the exposure volume and fume accumulation are thought to vary individually. This fact confirmed that the urinary chromium concentrations in stainless steel welders showed wide range, i.e., between 3.0 and $59.0 \mu \mathrm{g} / l$ and these values were smaller than those reported by other investigations. ${ }^{17,18)}$ It was not denied that the welders were exposed to ozone, although they wore personal respirators for protection against ozone and fumes, since in the welding procedures ozone and fumes were gnerated simultaneously. In general, it was considered that the chromosomes of peripheral blood lymphocytes in welders were not influenced by ultraviolet rays, since ultraviolet rays did not penetrate deeply into the skin. However, since very powerful ultraviolet rays were generated by stainless steel welding, particularly MIG welding, the influences of ultraviolet rays on the chromosomes in peripheral blood lymphocytes could not be completely denied either.

From the above facts, it was considered that the stainless steel welders were exposed to mutagenic complexes. Thus, our rsults showing structural chromosomal aberrations in lymphocytes from stainless steel welders would be confirmed. Furthermore, the increase of SCE frequency in lymphocytes from stainless steel welders was expected. However, the mean values of SCE frequency in welders were almost the same as those in the controls in both the first and the second surveys investigated the welders and the controls at the same time, whereas, the variances of SCE frequency in the welder group were larger than among the controls. Thus it was observed that in the SCE frequency of the welders, some subjects showed high values as compared with those of controls and some subjects showed low values as compared with those of controls. The reason for the fact that, in spite of exposure to mutagenic complexes, the low values of SCE frequency were shown by some welders was not clear. It was reported ${ }^{19,20)}$ that chromium plating workers who had been exposed to chromic acid $\left(\mathrm{CrO}_{3}\right)$ mist showed increased SCE frequency of blood lymphocytes. The mean chromium concentrations in the urine from these workers were almost the same or lower as compared with 
those of our study. It was clarified in the previous paper ${ }^{1)}$ that in the induced activity of SCE frequency, the chromium dissolved from fume particles generated by MMA welding in stainless steel welding was almost the same as chromium trioxide. In addition, stainless steel welding produces fume partciles containing nickel and manganese compounds other than chromium. These compounds also induce the increase of SCE frequency and cause chromosomal aberration in cultured cells. $^{21-23)}$ Thus, the reason why the increased incidence of SCE frequency in the stainless steel welders differed from that in the chromium plating workers could not be explained.

Husgavel-Pursianinen et al. ${ }^{17)}$ and Littorin et al. ${ }^{18)}$ investigated the chromosomes in the peripheral lymphocytes from stainless steel welders mainly engaged in MMA welding and reported that there was no significant difference between the welder group and the control group. It seems that there are differences between the fumes to which their workers were exposed and those affecting our subjects, because the welders in our study were engaged in stainless steel welding using both MMA welding and MIG welding as mentioned above. The in vitro experiment ${ }^{11}$ disclosed that chromium, which has the greatest ability to induce chromosome aberrations among all the metals contained in the fumes, was soluble in the fumes generated by MMA welding, but was insoluble in those produced by MIG welding. The latter type draws attention to its accumulation due to exposure and its long-term influences resulting from gradual solubilization in vivo.

The relationship between the number of cigarettes smoked per day and the SCE frequency was examined in the workers and controls, but the high frequency in the former group could not be explained in terms of smoking volume.

In the present study, slight but significant chromosomal changes in the peripheral blood lymphocytes from stainless steel welders were observed. Further investigations will be continued.

\section{ACKNOWLEDGEMENT}

The authors wish to express their sincere thanks to Mrs. K. Suzuki of this institute for her excellent technical cooperation. The authors are also deeply indebted to Drs. H. Sakabe and K. Homma of this institute, Dr. M. Higurashi of Yamanashi Medical College, and Drs. A. Koizumi and K. Morimoto of University of Tokyo, Faculty of Medicine, and Dr. T. Sofuni of National Institue of Hygienic Sciences, for their invaluable advices.

\section{REFERENCES}

1) Koshi, K. (1979). Effects of fume particles from stainless steel welding on sister chromatid exchanges and chromosome aberrations in cultured Chinese hamster cells, Ind. Health, 17, 39. 
2) Guerrero, R. R., Rounds, D. E., Olson, R. S. and Hackney, J. D. (1979). Mutagenic effects of ozone on human cells exposed in vivo and in vitro based on sister chromatid exchange analysis, Environ. Research, 18, 336.

3) Fetner, R. H. (1962). Ozone-induced chromosome breakage in human cell cultures, Nature, 194, 793.

4) Zelac, R. E., Cromroy, H. L., Bolch, W. E., Dunavant, Jr. B. G. and Bevis, H. A. (1971). Inhaled ozone as a mutagen. 1. Chromosome aberrations induced in Chinese hamster lymphocytes, Environ. Res., 4, 262.

5) Merz, T., Bender, M. A., Kerr, H. D. and Kulle, T. J. (1975). Observations of aberrations in chromosomes of lymphocytes from human subjects exposed to ozone at a concentration of $0.5 \mathrm{ppm}$ for 6 and 10 hours, Mutation Res., 31, 299.

6) Rommelaere, J., Susskind, M. and Errera, M. (1973). Chromosome and chromat:d exchange in Chinese hamster cells, Chromosoma, 41, 243.

7) Rauth, A. M. (1970). Effects of ultraviolet light on mammalian cells in culture, Curr. Top. Radiat. Res., 6, 195.

8) Parrigton, J. M. (1972). Ultraviolet-induced chromosome aberrations and mitotic delay in human fibroblast cells, Cytogenetics, 11, 117.

9) Sjören, B. (1980). A retrospective cohort study of mortality among stainless steel welders, Scand. J. work environ. health, 6, 197.

10) Hedenstedt, A., Jenssen, D., Lidesten, B., Ramel, C., Rannug, U. and Stern, R. M. (1977). Mutagenicity of fume particles from stainless steel welding, Scand. J. work environ. health, 3, 203.

11) Forni, A., Cappelini, A., Pacifico, E. and Vigliani, E. (1971). Chromosome changes and their evolution in subjects with past exposure to benzene, Arch. Environ. Health, 23, 385 .

12) Heath, C. W. and Dumont, C. R. (1977). Chromosomal damage in men occupationally exposed to vinyl chloride monomer and other chemicals, Environ. Res., 14, 68.

13) Andersson, H. C., Tranberg, E. A., Uggla, A. H. and Zetterberg, G. (1980). Chromosomal aberrations and sister-chromatid exchanges in lymphocytes of men occupationally exposed to styrene in a plastic-boat factory, Mutation Res., 73, 387.

14) Homma, K., Yamaguchi, H., Yagami, T., Ohba, M., Sano, H. and Araki, Y. (1978). Improvement measures for industrial health in arc welding of special alloys, Doc. No. IIW-II-868-78, IIW-VIII-776-78, The 1978 Annual Assembly of the International Instituie of Welding in Dublin.

15) Yagami, T. (1979). Health hazard and its protective method in welding, Occupational Health (Japan), 20, 47 (in Japanese).

16) Goto, K., Maeda, S. and Sugiyama, T. (1978). Factors involved in differential Giemsastaining of sister chromatids, Chromosoma, 66, 351.

17) Husgafvel-Pursiainen, K., Kalliomaki, P. L. and Sorsa, M. (1982). A chromosome study among stainless steel welders, J. Occup. Med., 24, 762.

18) Littorin, M., Hogstedt, B., Stromback, B., Karlsson, A., Welinder, H., Mitelman, F. and Skerfung, S. (1983). No cytogenetic effects in lymphocytes of stainless steel welders, Scand. j. work. environ. health, 9, 259.

19) Sarto, F., Cominato, I., Bianchi, V. and Levis, A. G. (1982). Increased incidence of chromosomal aberrations and sister chromatid exchanges in workers exposed to chromic acid $\left(\mathrm{CrO}_{3}\right)$ in electroplating factories, Carcinogenesis, 3, 1011.

20) Stella, M., Montaldi, A., Rossi, R., Rossi, G. and Levis, A. G. (1982). Clastogenic effects of chromium on human lymphocytes in vitro and in vivo, Mutation Res., 101, 151.

21) Andersen, O. (1983). Effects of coal combustion products and metal compounds on sister chromatid exchange (SCE) in a macrophagelike cell line, Environ. Health Perspective, 47, 239. 
22) Ohno, H., Hanaoka, F. and Yamada, M. (1982). Inducibility of sister-chromatid exchanges by heavy-metal ions, Mutation Res., 104, 141.

23) Larranmendy, M., Popescu, N. C. and Dipaolo, J. A. (1981). Induction by inorganic metal salts of sister chromatid exchanges and chromosome aberrations in human and Syrian hamster cell strains, Environ. Mutagenesis, 3, 597. 